\title{
Privatização dos serviços de saneamento: uma análise qualitativa à luz do caso de Cachoeiro de Itapemirim (ES)
}

\author{
Privatization of water and sanitation services: a qualitative analysis in the light \\ of the case of Cachoeiro de Itapemirim, Brazil
}

\begin{abstract}
Thiago Guedes de Oliveira
Geógrafo e especialista em Estudos de Impacto e Licenciamento Ambiental pela Pontifícia Universidade Católica de Minas Gerais (PUC Minas). Mestre e doutorando em Saneamento, Meio Ambiente e Recursos Hídricos pela Universidade Federal de Minas Gerais (UFMG)

Sonaly Rezende

Engenheira Civil e mestre em Saneamento, Meio Ambiente e Recursos Hídricos pela UFMG. Doutora em Demografia pelo Centro de Desenvolvimento e Planejamento Regional da UFMG (CEDEPLAR/UFMG). Professora adjunta da Escola de Engenharia da UFMG
\end{abstract}

\section{Léo Heller}

Engenheiro Civil, mestre em Engenharia Sanitária. Doutor em Epidemiologia. Pós-doutor pela Universidade de Oxford, Inglaterra. Professor associado do Departamento de Engenharia Sanitária e Ambiental da UFMG

\section{Resumo}

O artigo analisa os argumentos utilizados para justificar e para contrapor os discursos de autores e instituições nacionais e internacionais favoráveis ao controle privado dos serviços de saneamento. A partir de dados coletados sobre a experiência de Cachoeiro de Itapemirim (ES), conclui que o Estado foi incapaz de prover à população serviços de qualidade, mas a concessão também não foi uma solução plenamente satisfatória para os usuários, pois apresentou muitos dos problemas recorrentes em outros locais, segundo relatado na literatura, como a fraca participação popular e a ausência de parcerias entre os diversos órgãos responsáveis pelo saneamento naquele município. A priorização de determinadas áreas, em detrimento de outras, bem como os aumentos praticados nos valores das tarifas cobradas, são outros pontos negativos levantados. Por fim, sugere como alternativa, a busca por um modelo de gestão menos discriminatório, pautado principalmente por um forte e efetivo controle social das decisões.

Palavras-chave: privatização; saneamento; Cachoeiro de Itapemirim.

\begin{abstract}
The article examines the arguments used to justify and to counter the rhetoric of national and international authors and institutions in favor of private control of sanitation services. From data collected on the experience of Cachoeiro de Itapemirim (Brazil), it concludes that the State was unable to provide quality services to the population, but the concession was not an entirely satisfactory solution for users, because it showed many of the recurring problems in other locations, according to reports in the literature, such as the low participation of the population and the lack of partnerships between the various agencies responsible for water and sanitation services in the municipality. The prioritization of certain areas over others, as well as increases in the amounts of fees charged, are other weaknesses found. Finally, it suggests, alternatively, the search for a less discriminatory management model, guided mainly by a strong and effective social control of decisions.
\end{abstract}

Keywords: privatization; sanitation; Cachoeiro de Itapemirim. 


\section{Introdução}

As recentes experiências nacionais e internacionais de gestão privada na área de saneamento, por meio da transferência de ativos mediante o pagamento de indenização, através de concessões por tempo determinado, ou ainda pela abertura de capital das empresas públicas nas bolsas de valores, vêm sendo sistematicamente analisadas e criticadas por uma série de autores, principalmente de outros países, que identificam falhas e incoerências nesse modelo, desconstruindo seus discursos e rebatendo argumentos favoráveis à sua adoção, com o auxílio de evidências empíricas. Evidentemente, trata-se de tema controverso, havendo um conjunto de outros especialistas que acentuam suas vantagens e benefícios.

Nesta reflexão, de grande relevância para o delineamento das políticas públicas, por vezes tem-se um confronto ideológico, carregado de assertivas baseadas em suposições de difícil generalização, sujeitas a exemplos e contra-exemplos. Há aqueles que promovem a organização dos serviços de saneamento em torno de estratégias de mercado, considerando que estes são bens privados. De outro lado, têm-se os que defendem o seu caráter de direito básico próprio da conquista da cidadania e da vida em comunidade, não se sujeitando a critérios de eficiência mercantil.

Segundo Heller e Castro (2007) e Castro (2008b), aqueles que dão respaldo a visões empresariais baseiam-se muitas vezes em análises meramente quantitativas, sem a preocupação com a qualificação social e política das reflexões apresentadas. Além da pobreza dos argumentos, verificam-se inclusive fragilidades metodológicas nos estudos, levando a resultados contraditórios, como no caso da avaliação da privatização do sistema de abastecimento de água em Guiné (CLARKE; MENARD e ZULUAGA, 2002), que concluiu pela elevação do bem-estar da população, mesmo constatando que diversos problemas persistiam, como a submedição do consumo, a baixa cobertura, as elevadas tarifas e o fraco relacionamento institucional.

Nesse sentido, especialistas do Banco Internacional para Reconstrução e Desenvolvimento (BIRD), antigo defensor da privatização no saneamento, vêm reconhecendo que a concessão dos serviços a empresas privadas tem trazido "resultados misturados" (RICHARD e TRICHE, 1994). Além disso, iniciam uma defesa do papel central do poder público na organização e fornecimento de serviços, já que o setor privado tem dificuldades para servir aos mais pobres (BANCO MUNDIAL, 2003). Isso aconteceria porque, segundo Melo e Jorge Neto (2007), apenas os serviços explorados nas capitais e nos municípios de grande porte são financeiramente atrativos, ao contrário daqueles de médio e pequeno porte, onde a população mais precisa.
Ignorando esses problemas, os defensores da presença privada argumentam - através de um discurso aparentemente técnico, mas pautado em uma visão neoliberal - que esta pode ser uma boa solução para a baixa taxa de cobertura em determinadas áreas, a pouca qualidade dos serviços, a corrupção, o empreguismo, a tolerância com a inadimplência, a ineficiência econômica e financeira, as interferências políticas, os privilégios, os gastos excessivos com custeio, e a falta de planejamento e de investimentos na expansão e renovação da infraestrutura (CASTRO, 2008a).

Esses seriam alguns dos benefícios encontrados por Vargas e Lima (2004) ao compararem três sistemas geridos pela iniciativa privada no Brasil, entre meados de 2001 e 2003 - Limeira (SP), Niterói (RJ) e uma concessão que englobava cinco municípios na Região dos Lagos (RJ). Os autores concluíram que, nos três casos, a privatização revelou-se uma alternativa para alavancar investimentos na expansão e melhoria dos serviços. Em Limeira, os recursos foram destinados às obras complementares de uma estação de tratamento de esgotos. Já nos casos do Rio de Janeiro, ficaram focados na expansão e melhoria do abastecimento de água.

Fujiwara (2005) vai além ao afirmar que a privatização dos sistemas de saneamento teve relação direta com a redução da mortalidade infantil por doenças infecciosas e parasitárias, em municípios estudados em São Paulo e no Rio de Janeiro, devido aos impactos positivos para a qualidade dos serviços ofertados, sobretudo no abastecimento de água, que apresentou melhoria dos indicadores analisados e beneficiou a população menos favorecida. Esta conclusão seria contrária à ponderação de que, mesmo que a desestatização eleve a produtividade de certos setores, estes ganhos de eficiência são absorvidos pelas empresas ou apenas transmitidos às elites mais ricas.

Bayliss (2001), Hukka e Katko (2003), Mello (2005), Heller e Castro (2007), Hall e Lobina (2007) e Castro (2007; 2008a; 2008b) discordam dessa posição e observam que a maioria das experiências de atuação privada mostrou efeitos perversos e abaixo das expectativas, pois os investimentos foram inexistentes ou não atingiram o pactuado. Além disso, muitas vezes contaram com subsídios públicos, priorizaram o abastecimento de água e concentraram-se em regiões onde o retorno financeiro seria garantido. A propriedade dos ativos, por sua vez, continuou com o Estado, ocasionando o desinteresse por sua manutenção ao final das concessões. Já as tarifas foram elevadas para garantir o funcionamento dos sistemas e dos órgãos reguladores, onerando as parcelas pobres da população. Assim, a pobreza e a desigualdade, ao invés de combatidas, foram agravadas.

Por essas e outras razões, Heller e Castro (2007) argumentam que os enfoques privatistas sobre o saneamento merecem uma avaliação crítica, na medida em que tentam substituir o princípio desses serviços como um direito atrelado aos interesses e 
demandas sociais, por outros mercantis, subordinando as necessidades sociais aos requerimentos de eficiência empresarial. Nesse modelo, o cidadão passa a ser tratado como cliente e muitas vezes não tem assegurado o acesso aos serviços de qualidade, independentemente de sua inserção econômica, de sua classe, gênero ou etnia.

Outros problemas identificados envolvem a falta de concorrência, a dificuldade de revogar os acordos insatisfatórios, a pouca transparência, a consolidação dos interesses das elites dominantes e os casos de corrupção (HALL, 2001; BAYLISS, 2002; HALL; LOBINA, 2002). Também não há mecanismos sólidos de regulação, uma vez que as operadoras não se sujeitaram a sanções impostas pelo descumprimento de metas, ocasionando gestões ineficientes e o comprometimento da qualidade dos serviços, com consequências perversas para os usuários (PEROSA, 2002). De acordo com Galvão Júnior e Monteiro (2006), esta seria uma responsabilidade do Estado, que deveria definir a política tarifária, acompanhar a execução dos contratos e controlar a qualidade, através de órgãos devidamente qualificados para tal.

Na prática, a carência de leis apropriadas para regulamentar questões conflitantes e a falta de vontade política para discutir estes instrumentos podem ser fatores explicativos para a baixa qualidade da prestação dos serviços em várias partes do mundo. Devido a essa indefinição no ambiente regulatório, os concessionários usualmente correm riscos e procuram cobrar por isso. Os reajustes das tarifas costumam ser então implementados sem regras claras, protegendo as empresas de situações que elas poderiam suportar. Já os usuários se vêem obrigados a arcar com custos que poderiam ser atribuídos a outros agentes envolvidos (MELLO, 2005). Esse fator, somado à ausência de mecanismos de controle social, tem levado à crescente apatia dos usuários, que abrem mão de seus direitos e responsabilidades (CASTRO e LACABANA, 2005).

Segundo Ogera e Philippi Jr. (2005), também não interessaria à população se a gestão do saneamento é municipal ou estadual, bem como não importaria se é pública ou conta com participação privada. Para os usuários, a maior preocupação seria o atendimento às suas necessidades básicas, através da prestação de serviços de qualidade satisfatória. Essa afirmação, todavia, confronta um argumento dos defensores da privatização, haja vista que os autores assumem como verdade que tanto os gestores públicos, independentemente do nível, como os privados, são capazes de prestar bons serviços, preenchendo requisitos de viabilidade econômica, equidade social e sustentabilidade ambiental.

Acontece que nem sempre a iniciativa privada está preparada para oferecer os serviços básicos de saneamento com a qualidade e a universalidade necessárias, por um preço socialmente justo, pois esses objetivos podem contrastar com os princípios comerciais, os aspectos econômicos, as estratégias e forças de mercado, defendidos por Cowen e Cowen (1998) e Rouse (2009) como essenciais na reflexão sobre o saneamento. Neste sentido, Flores (2006) explica que a gestão dos bens públicos não deve necessariamente ser feita da mesma forma que a dos bens privados, mas precisa se voltar para atender às demandas sociais de forma eficiente e em bases sustentáveis, tanto do ponto de vista socioeconômico como ambiental.

Foi por isso que, em alguns países desenvolvidos, o Estado teve um papel fundamental na regulamentação e controle do setor, bem como no investimento direto para a expansão das redes e universalização dos serviços durante décadas, embora em contextos históricos, socioeconômicos e culturais totalmente diferentes da realidade brasileira. Naquele cenário, a regulação, o controle e a fiscalização das ações ficaram a cargo de instituições capazes de atuar com propriedade e justiça, de acordo os verdadeiros interesses e necessidades da coletividade (HELLER e CASTRO, 2007; CASTRO, 2008b).

Mas Hall (2001) defende que o poder público tem capacidade de administrar com êxito o saneamento também nos países em desenvolvimento, como nos casos de Debrecen, na Hungria, de Lilongwe, no Malawi, e de Tegucigalpa, em Honduras. Como pontos positivos, o autor destaca que as companhias públicas em geral são bem classificadas segundo indicadores de eficiência e contam com o apoio da comunidade, além de terem maior autonomia para concederam incentivos e subsídios para os usuários.

Acontece que as experiências positivas de gestão pública e as lições fundamentais da história são frequentemente ignoradas, fazendo com que muitos erros cometidos sejam repetidos. Este seria o caso do Brasil, na opinião de Turolla e Ohira (2007), pois o país teria seguido o mesmo caminho de outros emergentes, entre eles a Argentina, onde a privatização se deu de forma apressada, sem a definição de um marco regulatório e resultando em consequências indesejadas.

Para explorar a situação da atuação do capital privado na concessão de serviços de saneamento no Brasil, tema ainda pouco avaliado, desenvolveu-se um estudo no município de Cachoeiro de Itapemirim, no Espírito Santo, reconstituindo e analisando o processo de privatização, bem como a transição dos modelos de gestão dos sistemas de abastecimento de água e esgotamento sanitário. Além disso, avaliou-se a percepção de diversos atores sobre as mudanças ocorridas naquele município desde 1998, quando a Prefeitura anunciou o grupo vencedor da disputada Concorrência Pública no 06/97, o qual passou a controlar os serviços por um período de 37 anos e 6 meses, contados a partir daquele momento, em substituição à autarquia municipal.

Este trabalho fez parte de um projeto mais abrangente, financiado pela Fundação Nacional de Saúde (FUNASA) e realizado 
Tabela 1 - Participantes dos grupos focais

\begin{tabular}{lccccccc} 
& & & & \multicolumn{2}{c}{ Bairro Paraíso } \\
\cline { 2 - 4 } & Grupo 1 & Grupo 2 & Total & Grupo 3 & Grupo 4 & Total \\
Homens & 3 & 2 & 5 & 3 & 4 & 7 \\
Mulheres & 10 & 7 & 17 & 7 & 4 & 11 \\
Total Geral & 13 & 9 & 22 & 10 & 8 & 18 \\
\hline
\end{tabular}

Tabela 2 - Participantes das entrevistas semiestruturadas

\begin{tabular}{lcc} 
Instituição & Sigla atribuída & $\begin{array}{c}\text { Número de } \\
\text { entrevistados }\end{array}$ \\
\hline Agência Reguladora & AGR & 01 \\
\hline Câmara Municipal de Vereadores & CMV & 01 \\
\hline Conselho Municipal de Saneamento & CSN & 01 \\
\hline Conselho Municipal de Saúde & CMS & 01 \\
\hline $\begin{array}{l}\text { Autarquia Municipal e Empresa } \\
\text { Concessionária }\end{array}$ & EPC & 01 \\
\hline $\begin{array}{l}\text { Federação das Associações de } \\
\text { Moradores e Movimentos Populares }\end{array}$ & FAM & 01 \\
\hline $\begin{array}{l}\text { Prefeitura Municipal } \\
\text { Secretaria Municipal de Meio } \\
\text { Ambiente }\end{array}$ & PMC & 01 \\
\hline $\begin{array}{l}\text { Sindicato dos Trabalhadores na } \\
\text { Área de Saneamento e Empresa } \\
\text { Concessionária }\end{array}$ & SMA & 01 \\
\hline \begin{tabular}{l} 
Total \\
\hline
\end{tabular} & STS & 01 \\
\hline
\end{tabular}

em três municípios do Espírito Santo, que se dedicou à avaliação comparativa da gestão de serviços de saneamento em diferentes modelos institucionais.

\section{Métodos}

O primeiro passo do estudo consistiu em uma visita exploratória para levantamento de fontes secundárias relevantes. Foram realizados ainda os primeiros contatos com informantes-chave e lideranças locais, para o planejamento de entrevistas semiestruturadas e grupos focais. Estas dinâmicas foram executadas em outro momento, seguindo os procedimentos relatados e exemplificados na literatura especializada (FLICK, 2004; MINAYO, 2006; GASKELL, 2007).

As lideranças foram recrutadas com o auxílio de agentes e enfermeiros do Programa de Saúde da Família em dois bairros: o Gilson Carone - caracterizado por assentamentos irregulares, pelo baixo nível socioeconômico e condições precárias de vida - e o Paraíso - de ocupação mais antiga, melhor infraestrutura e nível socioeconômico mais elevado. Esta diversidade foi importante para que as realidades dos moradores pudessem ser confrontadas ao final dos grupos focais, que contaram com um número elevado de participantes, conforme detalhado na Tabela 1.

Além da atuação destacada em diferentes áreas, mas principalmente junto às igrejas e associações comunitárias, todos os participantes eram chefes de família e já residiam na cidade à época da concessão dos serviços, tendo vivenciado o processo de transição entre os modelos de gestão do saneamento. Tais condições foram imprescindíveis para que pudessem interagir com desenvoltura e discutir com propriedade as questões levantadas.

Já as entrevistas semiestruturadas contaram com a participação de governantes, gestores e técnicos, previamente identificados pelo seu notório conhecimento sobre o assunto pesquisado. Estes informantes desempenharam um papel de destaque para a gestão ou o controle do saneamento no município à época da privatização e nos anos subsequentes, devido às posições de comando que ocuparam, ou ainda ocupam, em diferentes instituições ligadas ao setor, como pode ser observado na Tabela 2.

Através das experiências e percepções pessoais desses atores, foi possível tratar de temas complexos e explorá-los em maior profundidade, elucidando pontos que não estavam claros nos relatos e documentos oficiais existentes, bem como esclarecendo as questões mais polêmicas levantadas anteriormente durante a realização dos grupos focais.

As gravações realizadas durante as dinâmicas foram transcritas e interpretadas a partir de métodos de Análise de Conteúdo. Realizou-se ainda uma Análise do Discurso dos atores, através do estabelecimento de relações entre as principais ideias e os contextos em que foram expressas, revelando sentidos aparentemente ausentes e trazendo à tona os interesses que moveram a sua construção (BARDIN, 2004; VERGARA, 2004; ROCHA; DEUSDARÁ, 2005; BAUER, 2007; GILL, 2007).

$\mathrm{Na}$ apresentação dos resultados, procurou-se construir um diálogo entre as ideias de todos os sujeitos a respeito de cada tópico, mas as suas identidades foram preservadas, conforme 
estabelecido no Termo de Consentimento Livre e Esclarecido assinado pelas partes envolvidas. Desta forma, as falas de cada participante dos grupos focais não foram associadas ao seu nome, mas a um código, conforme o exemplo a seguir: $\mathrm{GFX}_{1} \mathrm{PX}_{2}$, em que $\mathrm{X}_{1}$ identifica o número do grupo e $\mathrm{X}_{2}$ refere-se à localização do participante ao redor da mesa, progredindo em sentindo horário, a partir da posição do mediador. Os entrevistados, por sua vez, foram identificados pela sigla atribuída à instituição à qual estiveram ou ainda estão ligados.

\section{Resultados e discussão}

O caso de Cachoeiro de Itapemirim insere-se no mesmo contexto e não difere muito das experiências de participação privada no fornecimento dos serviços de saneamento, amplamente relatadas na literatura internacional, embora com algumas particularidades devido ao panorama local. O caráter político desta mudança no modelo de gestão revelou-se pela forte pressão exercida sobre os poderes executivo e legislativo do município, em meados da década de 1990, numa conjuntura neoliberal que estimulava a privatização de bens públicos em todo o país. O principal instrumento de coação era a restrição no acesso aos financiamentos. Neste sentido, "o governo federal não repassava [recursos]" (EPC). Segundo os autores envolvidos, "a privatização era um conselho do governo" e "[somente com] a concessão, haveria dinheiro para os serviços" (PMC). Além disso, "houve interesses econômicos poderosos" (SMA) em jogo, por parte de grupos que se aproveitaram oportunamente da situação, uma vez que "se apresentaram grandes empresas nacionais para participar [da licitação]" (AGR).

Os usuários, em sua grande maioria, estavam insatisfeitos com a qualidade dos serviços prestados pelo antigo Serviço Autônomo de Água e Esgotos (SAAE), cujos equipamentos e redes estavam obsoletos devido à falta de investimentos. Para eles, "não tinha outra saída; (...) ou [se] fazia isso ou Cachoeiro ficava sem água" (CMV). Alternativas não foram debatidas porque "não há o que discutir quando não se tem opção" (AGR). Este panorama acabou por legitimar a iniciativa privatista dos governantes e gestores locais em um contexto de baixa articulação e mobilização das forças populares, incapazes de participar das decisões, que, por sua vez, acabaram pouco transparentes. De acordo com os atores, a decisão "foi meramente política", pois o processo "não foi debatido com as comunidades, não foi discutido" (CMS). As maiores resistências à transição dos modelos de gestão se deram por parte de servidores municipais receosos de "perder o emprego e não ter as mesmas vantagens que eles tinham [antes]" (PMC). Mas estes também não conseguiram impedir a aprovação da proposta na Câmara de Vereadores, "porque era tudo dentro do contrato" (EPC).
Consolidada a concessão, os esforços da Prefeitura concentraram-se na criação de mecanismos jurídicos e institucionais necessários à boa gestão do saneamento no Município. Até aquele momento, não havia marcos jurídicos bem definidos para a área e a estrutura de controle e fiscalização era incipiente. A política pública instituída através da Lei Municipal nº 4.797/99 constituiu, sem dúvidas, um grande avanço frente à situação anterior, mas, segundo o representante do Conselho Municipal de Saneamento (CSN), "o satisfatório seria que os projetos de saneamento, que a Política de Saneamento fossem debatidos e referendados". O representante da Secretaria Municipal de Meio Ambiente (SMA) também declarou considerar importante "desenvolver essa interação com a comunidade, (...) [para] um resultado mais satisfatório". No entanto, o documento foi pensado e promulgado por gestores e governantes sem a devida discussão junto à população e, desta forma, muitos pontos acabaram não saindo do papel.

O CNS e as audiências públicas, por exemplo, ainda não estão funcionando conforme o previsto, principalmente no que se refere à periodicidade das reuniões e à presença da população, que "sabe reclamar, [mas] não comparece" (P8G1). Os demais canais de participação formalmente instituídos pela Prefeitura e pela Concessionária permanecem pouco conhecidos e utilizados. Falta organização, preparo, informação e interesse aos usuários para se fazerem representar. Eles mesmos reconhecem que "o povo ainda não aprendeu [a participar]" e, desta forma, "é muito difícil ter (...) um protesto, uma caminhada, um movimento com uns gatinhos pingados" (P3G4). Este distanciamento não permite, portanto, que haja um efetivo controle social dos serviços de saneamento de Cachoeiro de Itapemirim, com um verdadeiro "debate aberto e de prioridades" (P9G3).

Já a Agência Reguladora conta com autonomia financeira para funcionar, mas não se pode dizer o mesmo a respeito do aspecto político, uma vez que a ocupação dos cargos de diretoria é feita por "pessoas nomeadas pela Prefeitura, (...) [que] nunca ficam do lado da população (FAM)", posicionando-se frequentemente a favor dos interesses da Prefeitura ou da Concessionária. Os mandatos coincidem com o período de gestão do chefe do poder executivo e os dirigentes podem ser trocados ao final de cada processo eleitoral. A isenção do órgão para fiscalizar e controlar os serviços, bem como para mediar os possíveis conflitos entre as partes envolvidas, fica comprometida, porque ele é "autônomo, mas (...) pode ser usado de forma deturpada no processo" (SMA).

Mais um problema é o desencontro entre as diferentes instituições, que não assumem suas responsabilidades diante das reivindicações dos usuários por alguma melhoria, pois "cada uma está norteando no seu caminho e não existe um conjunto 
de discussões" (CMS). Outras vezes, competem entre si pela mesma atribuição ou pela divisão dos recursos financeiros disponíveis, e ficam "naquele jogo de empurra um pra cima do outro" (P8G1). Há uma carência de ações integradas e coordenadas entre os níveis de governo, a Agência Reguladora e a Empresa Concessionária. Faltam também programas conjuntos com outras áreas afins, como saúde, meio ambiente, obras, habitação e educação, entre outras. Como declara o representante da Agência Reguladora local, "é cada um achando que sabe fazer melhor (AGR)".

Mesmo com todos os problemas descritos, há a percepção, por parte da população, de grande melhoria na qualidade dos serviços prestados após a privatização. Ante à precariedade do sistema e à ausência de recursos financeiros no período que a antecedeu, comparados aos investimentos com recursos públicos subsidiados que se seguiram, algumas falas deixam clara a mudança positiva: "em relação [ao que era antes], melhorou" (CSN); "em vista do que era, melhorou" (FAM). Entretanto, foi notória a preferência pelos serviços de abastecimento de água em detrimento do esgotamento sanitário, bem como a prioridade dada às áreas mais desenvolvidas e centrais da cidade, devido ao maior retorno financeiro. As periferias e a zona rural ficaram em segundo plano: "lá [no Centro] fizeram uma rede; nós [moradores da periferia] não temos essa rede" (P7G2); "a área rural não (...) faz parte do Contrato de Concessão" (EPC).

As melhorias alcançadas, todavia, não teriam compensado os aumentos praticados pela Concessionária nas tarifas cobradas dos usuários, que acabaram financiando a expansão das redes. Para alguns participantes dos grupos focais, "se pensar pelo lado do custo, não [foi uma boa mudança]" (P5G3), porque "proporcionalmente, antes, com o SAAE, se pagava menos" (P7G4). Os valores referentes ao esgotamento sanitário, em especial, foram bastante contestados, pois, com o respaldo da justiça e da lei municipal, ele já "está sendo cobrado, [mas] não está, de fato, efetivado" (SMA). Assim, os cidadãos acabam pagando "por um serviço que não tem [disponível] (P4G1)”. O orçamento de inúmeras famílias ficou seriamente comprometido ao ponto de "estar faltando na mesa, (...) faltando o essencial" (P1G3).

Esta situação não tende a mudar após a venda da empresa ocorrida em 2008 para novos controladores que, até agora, mantêm o mesmo modelo administrativo adotado anteriormente e prometem seguir à risca os termos do contrato vigente com a Prefeitura, respeitando as metas e valores previstos. Na verdade, "houve uma alteração de capital, mas a estrutura de ação, os empreiteiros, (...) os técnicos, todos são as mesmas pessoas"
(SMA). A antecipação e ampliação dos investimentos recentemente anunciados certamente obedecem a uma lógica de mercado, pois visam à expansão da sua base de clientes-consumidores e o aumento dos lucros futuros.

\section{Conclusões}

O caso de Cachoeiro de Itapemirim ilustra uma situação de falha do poder público em cumprir seu papel no fornecimento de serviços de abastecimento de água e esgotamento sanitário de qualidade a toda a população, fortalecendo os discursos favoráveis à atuação da iniciativa privada nesta área. Entretanto, os argumentos levantados nesse sentido não se sustentaram à luz da realidade posterior, haja vista o conjunto de fragilidades encontradas no novo modelo. Assim, a grande questão que se coloca seria: qual o mecanismo de gestão mais apropriado e viável para o saneamento no município ou mesmo no país?

Uma das chaves para a resposta a esta indagação pode, eventualmente, se encontrar no caso da província de Santa Fé, Argentina, descrito por Flores (2007), onde o poder público também não conseguiu prestar um serviço satisfatório e a concessão do sistema à iniciativa privada foi igualmente problemática, devido aos valores cobrados dos usuários. Insatisfeita, a sociedade local mobilizou-se para lutar pela construção de um novo modelo de serviço, pertencente ao Estado, mas controlado pela população, por meio de práticas de gestão horizontais, abertas e participativas. Embora as propostas da Asamblea local não tenham se tornado realidade, uma vez que não conseguiram romper com o poder vigente, o nível avançado do debate e as sugestões elaboradas por aquela comunidade demonstram como um efetivo controle social seria enriquecedor para o avanço da gestão do saneamento.

Seguindo este caminho, o Estado, com a ajuda dos usuários, poderia adquirir capacidade de prover serviços de melhor qualidade a todos, sem discriminação de classe social ou favorecimento de alguma região. Esta reflexão pode contribuir para o aprimoramento dos modelos de gestão predominantemente adotados no país.

\section{Agradecimentos}

Agradecemos à Fundação Nacional de Saúde pelo financiamento, à pesquisadora Marluce Martins de Aguiar pelo apoio na coleta dos dados, e a todos os atores de Cachoeiro de Itapemirim que gentilmente se disponibilizaram a participar deste estudo. 


\section{Referências}

BANCO MUNDIAL. World development report 2004: making services work for poor people. Washington D.C.: Banco Mundial, 2003.

BARDIN, L. Análise de Conteúdo. 3.ed. Lisboa: Edições 70. 2004. 225 p.

BAUER, M.W. Análise de conteúdo clássica: uma revisão. In: BAUER, M.W.; GASKELL, G. (orgs.). Pesquisa qualitativa com texto, imagem e som: um manual prático. 6. ed. Petrópolis: Vozes, 2007. p. $189-243$.

BAYLISS, K. Privatization and poverty: the distributional impact of utility privatization Centre on Regulation and Competition - Working Paper: Manchester, n. 16, 2001. 16 p.

Water Privatisation in Africa: Lessons from three case studies. Greenwich: Public Services International Research Unit (PSIRU), University of Greenwich, 2001. Disponível em: <http://www.psiru. org/reports/2001-05-W-Africases.doc>. Acesso em: 14 abr. 2009.

CACHOEIRO DE ITAPEMIRIM. Lei 4.797/99 de 14 de julho de 1999. Dispõe sobre a Política Municipal de Saneamento, seus instrumentos e dá outras providências. Cachoeiro de Itapemirim, 1999.

CASTRO, J.E.; LACABANA, M. Agua y Desarrollo en América Latina: por una democracia sustantiva en la gestión del agua y sus servicios. $C D C$, v. 22, n. 59, p. 01-2, 2005.

CASTRO, J.E. Neoliberal water and sanitation policies as a failed development strategy: lessons from developing countries. Progress in Development Studies, v. 8, n. 1, p. 63-83, 2008b.

Poverty and citizenship: sociological perspectives on water services and public-private participation. Geoforum. v. 38. p. 756-71, 2007.

Proposiciones para el examen teórico y empírico de la privatización: el caso de los servicios de agua y saneamiento en América Latina. In: El agua, derecho humano y raíz de conflictos. Zaragoza, Spain: Government of Aragon, Fundación Seminario de Investigación para la Paz (SIP), p. 367-90, 2008a.

CLARKE, G.R.G.; MENARD, C.; ZULUAGA, A.M. Measuring the welfare effects of reform: urban water supply in Guinea. World Development, v. 30, p. 1517-37, 2002.

COWEN, P.B.; COWEN, T. Deregulated private water supply: a policy option for developing countries. Cato Journal, v. 18, p. 21-41, 1998.

FLICK, U. Uma introdução à Pesquisa Qualitativa. 2. ed. Porto Alegre: Bookman, 2004. 312p.

FLORES, R.K. O discurso como estratégia de luta contra a mercantilização da água. In: Colóquio internacional sobre poder local, 10, 2006, Salvador. Anais... Salvador, 2006.

A contra-hegemonia e a reestatização dos serviços de água e saneamento no Uruguai e na Província de Santa Fé (AR).
Dissertação (mestrado) - Universidade Federal do Rio Grande do Sul, Porto Alegre, 2007

FUJIWARA, T. A privatização beneficia os pobres? Os efeitos da desestatização do saneamento básico na mortalidade infantil. In: Encontro Nacional de Economia, 33, 2005, Natal. Anais... Natal: ANPEC, 2005.

GALVÃO JUNIOR, A.C; MONTEIRO, M.A.P. Análise de contratos de concessão para a prestação de serviços de água e esgoto no Brasil. Engenharia Sanitária e Ambiental, v. 11. n. 4. p. 353-361, 2006.

GASKELL, G. Entrevistas individuais e grupais. In: BAUER, M.W.; GASKELL, G. (orgs.). Pesquisa qualitativa com texto, imagem e som: um manual prático. 6. ed. Petrópolis: Vozes, 2007. p. 64-89.

GILL, R. Análise de discurso. In: BAUER, M.W.; GASKELL, G. (orgs.). Pesquisa qualitativa com texto, imagem e som: um manual prático. 6.ed. Petrópolis: Vozes, 2007. p.244-270.

HALL, D. El agua en manos públicas. La administración del agua en el sector público: una opción necesaria. Informe de la Internacional de Servicios Públicos (ISP), 2001. 33 p.

HALL, D.; LOBINA, E. From a private past to a public Future? The problems of water in England and Wales. Greenwich: Public Services International Research Unit (PSIRU), University of Greenwich, 2007. Disponível em: <http://www.psiru.org/reports/2008-02-W-UK.doc.> Acesso em: 14 abr. 2009

La privatización del agua en América Latina. Informe a la Conferencia Sobre el Agua de la ISP Américas. San José, Costa Rica, 2002. 36 p.

HELLER, L.; CASTRO, J.E. Política pública de saneamento: apontamentos teórico-conceituais. Engenharia Sanitária e Ambiental, v. 12. n. 3. p. $284-295,2007$

HUKKA, J.J., KATKO, T.S. Refuting the paradigm of water services privatization. Natural Resources, Forum 27, p. 142-155, 2003.

MELLO, M.F. Privatização do setor de saneamento no Brasil: quatro experiências e muitas lições. Revista de Economia Aplicada, São Paulo, v. 8, n. 3, p. 495-517, 2005.

MELO, J.A.M.; JORGE NETO, P.M. Bem-estar social, regulação e eficiência no setor de saneamento básico. In: Encontro Nacional de Economia, 35, 2007, Recife. Anais. Recife: ANPEC, 2007.

MINAYO, M.C. O desafio do conhecimento: pesquisa qualitativa em saúde. 10. ed. Rio de Janeiro: Hucitec, 2006. 403 p.

OGERA, R.C.; PHILIPPI JR., A. Gestão dos serviços de água e esgoto nos municípios de Campinas, Santo André, São José dos Campos e Santos, no período de 1996 a 2000. Revista Engenharia Sanitária e Ambiental, v. 10, n. 1, p. 72-81, 2005. 
PEROSA, R.T.Y. Regulação dos serviços de saneamento básico: aspectos conceituais e fatores intervenientes. Dissertação (mestrado). Faculdade de Saúde Pública/USP. São Paulo, 2002.

RICHARD, B., TRICHE, T.A. Reducing regulatory barriers to privatesector participation in Latin America's water and sanitation services. In: World Bank Policy Research Working Papers 1322. Washington DC: Water and Urban Development Department, The World Bank, 1994.

ROCHA, D; DEUSDARÁ, B. Análise de Conteúdo e Análise do Discurso: aproximações e afastamentos na (re)construção de uma trajetória. ALEA, v. 7. p. 305-322, 2005.

ROUSE, M. The market-centred paradigm. In: CASTRO, J.E.;
HELLER L. (orgs.). Water and Sanitation Services: public policy and management. London: Earthscan, 2009.

TUROLLA, F.A.; OHIRA, T.H. Pontos para uma discussão sobre eficiência e regulação em saneamento. In: SALGADO, L.H.; MOTTA, R.S. (orgs.). Regulação e concorrência no Brasil: governança, incentivos e eficiência. Rio de Janeiro: IPEA, v. 2, 2007. p. 197-215.

VARGAS, M.C.; LIMA, R.F. Concessões privadas de saneamento no Brasil: bom negócio para quem? Ambiente \& Sociedade, v. 7 , n. 2, 2004.

VERGARA, S.C. Métodos de pesquisa em administração. São Paulo: Atlas S.A, 2004. 287 p. 